\title{
SENYAPAN DALAM UJARAN ISYANA DAN CINDERCELLA PADA VIDEO TALKSHOW “METAL” DI YOUTUBE
}

\author{
Silence at Isyana and Cindercella's Speech at Talk Show Youtube Video
}

\section{Latu Parisa Nurjakia ${ }^{\text {** }}$ \\ Kholid A. Harras ${ }^{2}$ \\ Jatmina Nurhadi ${ }^{3}$

\author{
*IUniversitas Pendidikan \\ Indonesia, Bandung, Jawa \\ Barat, Indonesia \\ 2Universitas Pendidikan \\ Indonesia, Bandung, Jawa \\ Barat, Indonesia \\ 3 IUniversitas Pendidikan \\ Indonesia, Bandung, Jawa \\ Barat, Indonesia \\ *email: latuparisa@upi.edu
}

\begin{abstract}
Abstrak
Penelitian ini merupakan penelitian terhadap fenomena senyapan dalam produksi ujaran Isyana dan Cindercella dalam talkshow ringan "Metal" di youtube. Metode yang digunakan yaitu metode kualitatif deskriptif dengan tujuan untuk mendeskripsikan temuan dari hasil analisis terhadap fenomena senyapan dalam produksi ujaran Isayana dan Cindercella di dalam video tersebut seperti jenis senyapan, distribusi senyapan, dan penyebab senyapan. Hasilnya ditemukan dua jenis senyapan di dalam video tersebut yaitu senyapan diam dan senyapan terisi yang meliputi senyapan yang terisi dengan bunyi, kata, pengulangan, dan kombinasi pengulangan. Distribusi senyapan semuanya berada di posisi tengah klausa. Ada pun penyebab terjadinya senyapan yaitu: (I) pengambilan napas, (2) pencarian kosakata yang tepat, (3) gugup, (4) lupa pada kosakata tertentu, (5) koreksi dari penutur, (6) keraguan, dan (7) penekanan pada kata tertentu.
\end{abstract}

\begin{abstract}
This research is a research on the phenomenon of silence in the production of Isyana and Cindercella's utterances in the light talk show "Metal" on YouTube. The method used is descriptive qualitative method with the aim of describing the findings from the analysis of the silent phenomenon in Isayana and Cindercella's speech production in the video, such as the type of silence, distribution of silence, and the causes of silence. The results found two types of silences in the video, namely silent silences and filled silences, which include silences filled with sounds, words, repetitions, and repetition combinations. The mute distributions are all in the middle of the clause. There are also causes of silence, namely: (I) taking a breath, (2) searching for the right vocabulary, (3) nervousness, (4) forgetting certain vocabulary, (5) correction from speakers, (6)

doubting, and (7) emphasis on a particular word
\end{abstract}

(c) 2021 The Authors. Published by Institute for Research and Community Services Universitas Muhammadiyah Palangkaraya. This is Open Access article under the CC-BY-SA License (http://creativecommons.org/licenses/by$\mathrm{sa} / 4.0 /)$.

\section{PENDAHULUAN}

Dalam kehidupan sehari-hari manusia tidak lepas dari kegiatan berkomunikasi. Salah satu aspek penting dari kegiatan berkomunikasi adalah bahasa. Namun, acap kali ditemukan adanya penggunaan bahasa ujaran yang mengalami kekeliruan berupa hambatan sehingga menimbulkan sebuah kesalah pahaman antara penutur dan petutur. Hambatan pada ujaran dalam ilmu bahasa disebut senyapan. Senyapan biasanya terjadi ketika penutur tidak dapat menyampaikan maksud tuturannya kepada lawan bicara atau petutur. Hambatan ketika bertutur ini dapat terjadi pada siapa saja termasuk pada pekerja seni seperti penyanyi dan influencer. Dalam beberapa kesempatan seperti ketika melakukan wawancara, konser, dan lain sebagainya tidak jarang artis dan influencer mengalami kekeliruan berupa hambatan ketika bertutur. Isyana Sarasvati dikenal sebagai penyanyi yang acap kali mengalami hambatan ketika ia sedang bertutur. Bahkan fans Isyana membuat sebuah video kompilasi dirinya yang beberapa kali 
mengalami kesalahan berupa hambatan bertutur ketika sedang konser, wawancara, dan tampil di talkshow. Selain Isyana ada juga Cindercella, yaitu seorang beauty vlogger yang juga dikenal sebagai influencer yang sering mengalami kekeliruan berupa hambatan ketika bertutur oleh fansnya.

Isyana dan Cindercella berkesempatan tampil bersama dalam sebuah talkshow ringan bernama "Metal (Makan Santei Tapi Endol)" yang diunggah di kanal youtube WAW Entertaiment pada tanggal 7 Mei 202I. Isyana dan Cindercella berbincang bahasan ringan soal kehidiupan mereka dari mulai keseharian, hobi, hingga karir. Dalam video yang berdurasi 48 menit itu juga, Isyana dan Cindercella melakukan beberapa tantangan seperti makan-makanan pedas dan kuis. Ujaran Isyana dan Cindercella dari awal terlihat lancar namun ada kecanggungan yang sepertinya hadir di antara mereka. Hal tersebut terlihat dari Isyana mau pun Cindercella yang berkali-kali menuturkan frasa mau pun kalimat yang putus-putus, ujaran tidak jelas, bahkan mengalami jeda.

Dalam psikolinguistik hambatan ujaran disebut sebagai senyapan sementara kekeliruan ujaran disebut kilir lidah. Hambatan pada ujaran bisa berupa interupsi seperti keterdiaman, pengucapan yang tidak berkaitan dengan pesan yang dimaksud (baik bunyi, kata, atau kalimat), pengulangan kata, dan hal-hal lain yang berindikasi terhadap sebuah tuturan yang tidak ideal. Hal tersebut sesuai dengan apa yang dikatakan oleh Dardjowidjojo (20I2) yang mengelaborasi bahwa tuturan ideal adalah tuturan yang lancar dari awal memulai tuturan hingga tuturan selesai. Dilengkapi dengan rangkaian kata yang rapat, dan selalu berkesinambungan, senyapan yang muncul berada pada waktu yang pas karena muncul saat memiliki sebuah kemunngkinan terjadinya senyapan. Hambatan seperti itu disebut senyapan jika dilihat secara teknis. Sementara Fraundorf dan Watson (2013) mengartikan senyapan sebagai sebuah hambatan gangguan verbal mau pun non-verbal yang tidak memiliki hubungan atau tidak menjadi sebuah bagian dari maksud atau pesan utama penutur.

Peristiwa senyapan yang terjadi pada Isyana dan Cindercella tentu perlu dikaji lebih dalam lagi guna memperkaya anlisis terkait studi psikolinguistik khususnya pada produksi ujaran. Ada pun penelitian sebelumnya yang sekaitan dengan penelitian ini yaitu penelitian dengan judul Senyapan dan Penyebabnya pda Debat Final Pemilihan Kepala Daerah Khusus Ibu Kota Jakarta Tahun 2017 oleh Novi Sasmitasari, Sisilya Sama, dan Patriantoro. Penelitian tersebut berfokus pada analisis senyapan dan penyebabnya pada debat final cpemilihan calon kepala daerah Ibu Kota Jakarta tahun 2017. Penelitian tersebut menajdi salah satu referensi dalam menganalisis dan mengelaborasi penelitian ini. Ada pun perbedaan analisis berada pada perbedaan fokus penelitian. Penelitian ini berfokus pada (I) jenis senyapan, (2) distribusi senyapan, dan (3) penyebab senyapan yang terjadi pada produksi ujaran Isyana dan Cindercella dalam talkshow "Metal (Makan Santei Tapi Endol) di kanal youtube WAW Entertaiment.

\section{METODOLOGI}

Metode Penelitian ini mengggunakan metode deskriptif kualitatif. Mendeskripsikan durasi senyapan, jenis senyapan, distribusi senyapan, dan penyebab senyapan yang terjadi pada video talkshow ringan dengan "Metal (Makan Santei Tapi Endol)" Isyana dan Cindercella di kanal youtube WAW Entertaiment. Selanjutnya penelitian ini menggunakan analisis psikolinguistik yang merupakan salah salah satu cabang ilmu bahasa. Psikolinguistik ini menganalisis hubungan antara bahasa dan akal atau psikis manusia.

Sumber data penelitian ini adalah produksi ujaran Isyana dan Cindercella yang berbincaang santai di acara talkshow ringan “Metal (Makan Santei Tapi Endol)” yang ada di kanal youtube WAW Entertaiment. Data penelitiannya berupa senyapan yang ada di dalam talkshow ringan "Metal (Makan Santei Tapi Endol)" Isyana dan Cindercella. Ada pun teknik yang digunakan 
dalam penelitian ini yaitu teknik simak catat dari video yang sebelumnya telah diunduh terlebih dahulu.

\section{HASIL DAN PEMBAHASAN}

Diperoleh data berupa senyapan dari acara "Metal (Makan Santei Tapi Endol)" di youtube yang dilakukan oleh Isyana dan Cindercella. Di bawah ini merupakan tabel penguraian secara singkat hasil analisis produksi ujaran berupa senyapan oleh Isyana dan Cindercella:

Tabel I. Produksi ujaran berupa senyapan Isyana dan Cindercella

\begin{tabular}{|c|c|c|c|}
\hline Pelaku & Waktu & Durasi/s & Narasi \\
\hline Cindercella & $5: 34$ & 10 & $\begin{array}{l}\text { Lu pada keren keren } \\
\text { banget bisa nyoret- } \\
\text { nyoret muka jadi kaya } \\
\text { kakak eh-kanvas }\end{array}$ \\
\hline Isyana & $6: 28$ & 15 & $\begin{array}{l}\text { Kamu tuh, sebenernya } \\
\text { bisa itu kan... bisa... } \\
\text { dandanin orang lain? }\end{array}$ \\
\hline Cindercella & $7: 10$ & 10 & $\begin{array}{l}\text { Sama! Agak ini... ini } \\
\text { aku enggak ngerti }\end{array}$ \\
\hline Cindercella & $8: 05$ & 15 & $\begin{array}{l}\text { Kaya takut... takut... } \\
\text { Mas Dedinya ke- } \\
\text { offened gitu ya? }\end{array}$ \\
\hline Isyana & $8: 49$ & 10 & $\begin{array}{l}\text {...dan Mas Dedi... Mas } \\
\text { Dedi... notis ya? }\end{array}$ \\
\hline Cindercella & $9: 45$ & 30 & $\begin{array}{l}\text { Aku tuh suka banget } \\
\text { make up yang... simple } \\
\text { gitu }\end{array}$ \\
\hline Cindercella & $1 \mathrm{I}: 10$ & 20 & $\begin{array}{l}\text { Tapi Mas Dedinya kok } \\
\text { e... lebih kecil ya }\end{array}$ \\
\hline Cindercella & $1 \mathrm{I}: 15$ & 10 & $\begin{array}{l}\text { Jadi, aku masuk... } \\
\text { ma... masuk ke tempat } \\
\text { party-nya tuh kaya gini }\end{array}$ \\
\hline Isyana & $14: 33$ & 10 & $\begin{array}{l}\text { Sumpah tapi... tapi... } \\
\text { kita bakalan... haha... } \\
\text { kita bakalan wah! gitu }\end{array}$ \\
\hline Isyana & $14: 42$ & 10 & $\begin{array}{l}\text { Bisa roll on eh rolling } \\
\text { haha }\end{array}$ \\
\hline Isyana & $15: 32$ & 15 & $\begin{array}{l}\text { Kita lihat se... jahat apa } \\
\text { mereka sama kita }\end{array}$ \\
\hline Isyana & $25: 36$ & 20 & $\begin{array}{l}\text { Ini samyang samat } \mathrm{e} . . \\
\text { selamat menikmati }\end{array}$ \\
\hline Isyana & $26: 20$ & 10 & $\begin{array}{l}\text { Senja eh senyawa pedas } \\
\text { ini }\end{array}$ \\
\hline Cindercella & $29: 03$ & 20 & $\begin{array}{l}\text { Tapi kalo misalkan ada } \\
\text { yang nyob... ada yang } \\
\text { kaya "aku pengen } \\
\text { nyobain tempat ini } \\
\text { deh" gitu ayo! }\end{array}$ \\
\hline Isyana & $31: 09$ & 10 & $\begin{array}{l}\text { Langsung... apa sih itu } \\
\text { namanya... langsung } \\
\text { kaya sedih gitu }\end{array}$ \\
\hline Cindercella & $31: 50$ & 10 & $\begin{array}{l}\text { Snek-snek yang kiloan } \\
\text { gitu eh kiloan, snek yang } \\
\text { gram-graman }\end{array}$ \\
\hline
\end{tabular}

Jenis Senyapan
Dardjowidjojo (2012) mengatakan bahwa senyapan memiliki dua macam yaitu ( $I$ ) senyapan diam dan (2) senyapan terisi. Senyapan diam ditandai dengan keterdiaman sejenak oleh penutur lalu setelah menemukan kata yang dicari maka penutur akan kembali melanjutkan kalimatnya. Pada video youtube talkshow ringan Isyana dan Cindercella ditemukan kedua jenis senyapan yakni senyapan diam dan senyapan terisi. Di bawah ini merupakan produksi ujaran senyapan jenis senyapan diam sebagai berikut:

I. Aku tuh suka banget make up yang... simpe gitu

2. Kita lihat se... jahat apa mereka sama kita

3. Tapi kalo misalkan ada yang nyob... ada yang kaya "aku pengen nyobain tempat ini deh" gitu, "ayo!”

Berikutnya ada produksi ujaran senyapan jenis senyapan terisi yang ditemukan di dalam video sebagai berikut:

I. Lu pada keren keren banget bisa nyoret-nyoret muka jadi kaya kakak eh-kanvas

2. Kamu tuh, sebenernya bisa itu kan... bisa... dandanin orang lain?

3. Sama! Agak ini... ini aku enggak ngerti

4. Kaya takut... takut... Mas Dedinya ke-offened gitu ya?

5. ...dan Mas Dedi... Mas Dedi... notis ya?

6. Tapi Mas Dedinya kok e... lebih kecil ya

7. Jadi, aku masuk... ma... masuk ke tempat party-nya tuh kaya gini

8. Sumpah tapi... tapi kita bakalan... haha... kita bakalan wah! Gitu

9. Bisa roll on eh rolling haha

10. Senyawa capsasin eh capsaicin murni itu... 
II. Ini samyang samat e... selamat menikmati

\section{Senja eh senyawa pedas ini}

13. Snek-snek yang kiloan gitu eh kiloan, snek yang gram-graman

Ditemukan adanya beberapa pengisi senyapan terisi seperti bunyi, kata, pengulangan, dan kombinasi senyapan. Senyapan terisi denngan bunyi yang terdapat pada produksi ujaran di dalam video yaitu bunyi [e] yang diujarkan dengan nada yang agak panjang sehingga mengisi senyapan. Senyapan terisi dengan kata yang terdapat pada produksi ujaran berupa kata: (I) eh, (2) kan, dan (3) ma. Senyapan terisi dengan pengulangan berada pada pengulangan kata dan frasa berupa: (I) bisa, (2) ini, (3) takut, (4) Mas Dedi, (5) masuk, dan (6) tapi. Ada pun senyapan terisi dengan kombinasi senyapan merupakan senyapan yang dikombinasikan dengan kilir lidar berupa: (I) penggunaan roll on kemudian disenyapkan dengan eh lalu digantikan dengan kata yang sebenarnya yaitu rolling, (2) capsasin yang disenyapkan dengan eh kemudian segera digantikan dengan kata capsaicin yang merupakan kata sebenarnya, (3) samat yang disenyapkan kemudian digantikan dengan selamat menikmati, (4) senja disenyapkan kemudian diganti oleh kata senyawa yang merupakan kata sebenarnya, (5) kakak mengalami senyapan kemudian digantikan oleh kanvas, dan terakhir (6) yaitu kiloan yang disenyapkan lalu diganti oleh gram karena penutur memang sedari awal bermaksud untuk mengatakan gram.

\section{Distribusi Senyapan}

Senyapan pada produksi ujaran Isyana dan Cindercella semuanya memiliki distribusi senyapan yang berada di tengah frasa. Berikut akan dipaparakan salah satu contoh pendistribusian senyapan yang ada pada produksi ujaran Isyana dan Cindercella yang terletak di tengah frasa sebagai berikut:

"Tapi Mas Dedinya kok e... lebih kecil ya" Dapat dilihat senyapan terisi berupa bunyi [e] terletak di tengah frasa setelah kata atau partikel kok. Senyapan tersebut termasuk ke dalam senyapan diam.

\section{Penyebab Senyapan}

Ada beberapa penyebab senyapan. Menurut Dardjowidjojo (2012) menyampaikan bahwa setiap orang dalam memproduksi ujaran akan senyap sebentar. Bisa untuk mengambil napas atuu pun keperluan lainnya yang mendesak. Sehingga akhirnya melahirkan berbagai alasan mengapa seseorang mengalami hambatan berupa senyapan ketika memproduksi ujaran. Ada tiga alasan utama yang melatarbelakangi terjadinya senyapan yaitu: (I) kesiapan, (2) lupa dengan kata-kata yang ingin diucapkan, dan (3) berhati-hati dalam memilih kata.

Mengacu pada ketiga alasan utama tersebut, berikut merupakan hasil analisis penyebab terjadinya senyapan dalam produksi ujaran Isyana dan Cindercella pada talkshow ringan "Metal (Makan Santei Tapi Endol)” di kanal youtube WAW Entertaiment. Berikut

I. Pengammbilan napas

"Kamu tuh, sebenernya bisa itu kan... bisa... dandanin orang lain?"

Penutur dengan sengaja membuat sebuah jeda atau senyap pada tuturannya untuk mengambil napas. Di dalam video terlihat bahwa penutur melakukan senyap pada kata bisa yang pertama. Namun, pada senyap selanjutnya merupakan sebuah senyapan yang tidak disengaja karena penutur lupa dengan kosakata yang ingin ia utjarkan.

2. Pencarian kosakata yang tepat

"Aku tuh suka banget make up yang... simpe gitu"

Penutur melakukan senyapan setelah kata yang sebagai bentuk refleks karena pencarian kosakata yang diinginkan dan sesuai dengan pesan yang ingin disampaikan. Akhirnya penutur berhasil menemukan kata yang tepat berupa kata simple dan itu seusai dengan apa yang ia ingin ujarkan.

3. Gugup 
"Lu pada keren keren banget bisa nyoret-nyoret muka jadi kaya kakak ehkanvas"

Tuturan ini merupakan tuturan yang berada pada awal-awal perbincangan mereka. Penutur masih mengalami kegugupan karena suasana masih canggung sehingga terjadi senyapan yang tidak disadari akibat kegugupan yang dirasakan oleh penutur.

4. Lupa pada kosakata tertentu

"Sama! Agak ini... ini aku enggak ngerti"

Penyebab keluputan kosakata ini sering terjadi pada setiap orang. Penutur di dalam video terlihat lupa dengan kosakata yang ingin ia ujarkan sehingga senyapan terjadi. Senyapan yang dilakukan adalah senyapan terisi dengan pengulangan kata. Biasanya dilakukan untuk merangsang otak untuk kembali mengingat kosakata yang ingin diujarkan.

5. Koreksi dari penutur

"Snek-snek yang kiloan gitu eh

kiloan, snek yang gram-graman”

Penutur melakukan senyapan terisi berupa eh di antara frasa kilon gitu dan kata kiloan sebagai sebuah pengkoreksian terhadap kesalahan kosakata yang diujarkan.

6. Keraguan

“Jadi, aku masuk... ma... masuk ke tempat party-nya tuh kaya gini”

Penutur mengalami keraguan ketika mengujarkan kata masuk. Itu terjadi karen penutur berujar sambil mengingat-ingat kejadian yang sedang ia ceritakan.

7. Penekanan pada kata tertentu

"Kita lihat se... jahat apa mereka sama kita”
Penutur melakukan senyapan pada pemenggalan kata sejahat seolah menekankan kata jahat agar mereka (yang dimaksud oleh penutur) merasa bahwa mereka jahat.

Penyebab dari senyapan bergantung pada konteks dan tujuan penutur ketika memproduksi sebuah ujaran.

\section{KESIMPULAN}

Senyapan merupakan salah satu kajian yang menarik dan penting dalam penelitian produksi ujaran. Penelitian senyapan perlu terus dilakukan agar informasi mengenai produksi ujaran semakin bertambah. Berdasarkan hasil penelitian yang dilakukan terhadap senyapan dalam produksi ujaran Isyana dan Cindercella dalam talkshow ringan "Metal (Makan Santei Tapi Endol) ditemukan jenis senyapan, distribusi senyapan, dan penyebab senyapan. Senyapan dari produksi ujaran Isyana dan Cindercella terdiri dari jenis senyapan diam dan senyapan terisi. Distribusi senyapan hanya berada pada posisi di tengah frasa. Ada pun penyebab dari senyapan tersebut yaitu: (I) pengambilan napas, (2) pencarian kosakata yang tepat, (3) gugup, (4) lupa pada kosakata tertentu, (5) koreksi dari penutur, (6) keraguan, dan (7) penekanan pada kata tertentu.

\section{REFERENSI}

Dardjowidjojo, S. 2012. Psikolingustik: Pengantar Pemahaman Bahasa Manusiai. Jakarta: Yayasan Pustaka Obor Indonesia.

Aitchison, J. 1988. The Articulate Mammal: An Introduction to Psycholinguistics. London: Routledge.

Tarigan, H., G. 2008. Berbicara Sebagai Suatu Keterampilan Berbahasa. Bandung: Angkasa.

Noleong, L., J. 2002. Metode Penelitian Kualitatif. Bandung: Pemuda Posda Karya.

Zaim, M. 2014. Metode Penelitian Bahasa: Pendekatan Struktural. Padang: UNP Press.

Pateda, M. 1989. Analisis Kesalahan. Flores: Nusa Indah. 